\title{
INTERDISCIPLINARY APPROACHES OF STUDYING THE PSYCHOSOMATIC INDICATORS OF DISABLED PEOPLE FOR THE AIMS OF MEDICAL PROGRAMMING AND ROBOTICS
}

\author{
Galina Bogdanova', Liana Galabova² \\ IInstitute of Mathematics and Informatics at BAS, Sofia, Bulgaria \\ 2 Free Researcher, Sofia, Bulgaria \\ galina@math.bas.bg, lianagalabova@abv.bg
}

\begin{abstract}
Constrained public reflection on the regression of glocal critical epidemic situation of spring 2020 provoked visible recent peak of the interest in advisability of direction of cultural priorities to robotics, not only in the fields of health and social care. Necessity of sufficient experience in socio-medical research and practice for achievement of quality innovations in the fields of medical software programming and robotics, recently could be most adequately expressed in mass direct measurements of psychophysical indicators of population on considered and new criteria and with regard of direct public advantages in particular pandemic conditions and in hardly prognosable sociocultural parameters of near future.

Keywords: Accessibility; Disabilities; Indicators; Measurements; Medicine; Software Robotics; Healthcare; Social Care, Labour Adaptation; Human Rights; Pandemics
\end{abstract}

\section{ИНТЕРАИСЦИПАИНАРНИ ПОАХОАИ НА ПРОУЧВАНЕ НА ПСИХОСОМАТИЧНИТЕ ПОКАЗАТЕАИ НА ХОРА С УВРЕЖААНИЯ ЗА ЦЕАИТЕ НА МЕАИЦИНСКОТО ПРОГРАМИРАНЕ И РОБОТИКАТА}

АОц. А-р инж. Галина БогАанова ', Аиана ГъАъбова ${ }^{2}$

' Институт по математика и инфоорматика към БАН, Соффия, България

${ }^{2}$ Свободен изслеловател, Софрия, България

Резюме: Изострената публична рефрлексия на развилата се през пролетта на 2020 година глокална кризисна епидемична ситуация преАизвиква видимия Анешен пик на интереса към целесъобразността от насочване на културните приоритети към роботиката, не само в областта на зАравеопазването и социалните грижи. Необходимостта от Аостатъчен изслеАователски и практически социално-меАицински опит за осъществяването на качествени иновации в областта на медицинското програмиране и роботика, понастоящем най-алекватно може $а$ се изрази в 
масови непосредствени измервания на психо фоизичните показатели на населението по общоприети и нови критерии и с оглеА на преки обществени ползи в конкретните пандемични условия и в трудните за прогнозиране социокултурни параметри на близкото бълеще.

КАючови Ауми: Аостьпност, УврежАания, показатели, измервания, медицина, програмиране, роботика, здравеопазване, социални грижи, труАова алаптация, човешки права, пандемия

ЗАравеопазването и социалните грижи са еАин от обществените сектори представителни за цялостното текущо глокално културно състояние на населението като човечество. СлеА Аосегашния застрашителен пик на миграциите налминаващи по острота и безизходност съвременните военни конфликти и бързо развиващото се състояние на високотехнологичните системи за сигурност, стереотипьт на регионалното социално неравенство изразен чрез сентенцията: "Мизерията създава таланти" все по-малко може да се отнесе към цивилизацията, която постепенно се офрормя слеА постмолерното инорормационно общество. Трудността $\Delta$ а се охарактеризира и Аефинира прогнозирания цивилизационен скок фоокусирал обществените тенденции чрез пандемия простираща се във времето не повече от един сезон, предстои да се разреши на пьрво място чрез отпалане на повечето от културните резерви на Аосегашните поколения към масовата социализация Аигитализацията, роботизацията и виртуалността като базови цивилизационни характеристики и ценностни ориентации.

Естественият риск от пореАното цикАично цивилизационно преповтаряне на предозирането на технологизация едва $\wedge$ и може $\Delta а$ застраши човечеството отвъА вече осъществените в Аоскоро немислими перспективи и мащаби биологични и социални експерименти, чиито последствия еАва започват $\Delta$ а се появяват на повьрхността на социалните процеси в хола на Аостигането им на прозрачност чрез новите медии. СлеА като чрез дигитализацията журналистиката и фотографиияа се масовизираха, Аемократизираха и лепродресионализираха, предстои съвременното човешко ценностно съзнание $а$ а се справи с високотехнологичните си стремежи към непрестанна споделена локация и изльчване на ежедневието си в 
реално време с Аоброволно сполеляне на ^ична инорормация с риска от Аева^вация на иАентичността.

Комуникациите и благоустройството без социалния си ореол на ^укс и разточителство връщат потребителската бизнес култура и ценността на туристическата рекреативна мобилност в преАмодерните исторически периоди, когато качеството на заравеопазването и нивото на социални грижи не е давало възможност на човечеството Аа премине ценностната граница на генната модификация неалекватна на реална социална потребност, чието тьрсене като продукт се налага като културна инАустрия и застрашава цивилизационни устои. Футуристичните редрлексии в изкуството като отглас от проАьАжитеАното културно творчество на рьба на социалната поносимост и конорликта Анес не са Аостатъчни $А$ о осъществят ценностен скок от миналото Към бълещето, тъй като реалността извеАнъж Аемонстрира несъстоятелност да разреши устойчиво проблемите на практиката.

\section{ТРАНСПОРТ И КОМУНИКАЦИИ}

Транспортните комуникации и инораструктури са еАна от сорерите, в които и чрез които основно се решават етичните общохуманни проблеми на миграцията, изолацията, снабляването, благоустройството и регионалното развитие. ЗаеАно с меАиите и комуникационните технологии тези сектори са са традиционно на пьрвата фонтова Аиния в кризисни ситуации и неотменно подсигуряват ресурси, вкАЮчително инорормация, в реално време като претьрпяват и негативите иАващи от парализирането на спорта и туризма с рекреативните и феестивалните събития като културни практики. СлеА кризисното подобряване на качеството на управление на селищните обществени структури предстои $\Delta$ а се повлияе и от повишаването на съзнанието за ключовата социална значимост на тези сектори, нареА с медицината и промишлеността занемарени за сметка на експорт и емиграция.

Постоянната разработка на нови технологии за целите на транспортните комуникации, вкА. програмни продукти за роботиката, обелинява значителен инженерен ресурс пьрвоначално предназначен за 
рискови сорери от отбраната през сигурноста и зАравеопазването $\Delta о$ социалните грижи за хора в неравностойно положение (Sabev, 2020), (Karagyozov, 2019), вк^ючително и кризисно и пост-травматично.

Благоустройствените придобивки, които чрез бизнеса и масовото потребление навлизат трайно в бита и значимо променят културните навици на населението, в повечето случаи не биха се реализирали в глобален мащаб, ако не бяха проектирани в отговор на високо специализирани и тясно профилирани профресионаАни нужАи. Изобретенията и внеАряванията, които успяват да променят света са иманентно заложени в стремежа да се промени живота, воден от усърАието в социалните грижи за вкАючването на неравностойни Аица и групи с цел те $\Delta$ а не застрашават материално и Ауховно обществото като цяло. Пандемията от 2020 нелвусмислено Аемонстрира риска от застрашаване на благополучието на елитите при висока степен на нарушаване на егалитарния баланс, който забележимо очертава цивилизационни послеАствия [Фиг. 1].

\begin{tabular}{|c|c|c|c|c|}
\hline HAЗЕMEH & ПОАЗЕМЕН & $\begin{array}{c}\text { BOАЕН И } \\
\text { ПОАВОАЕН }\end{array}$ & ВЪЗАУШЕН & КОСМИЧЕСКИ \\
\hline $\begin{array}{l}\text { Снабдяване, } \\
\text { сигурност, } \\
\text { отбрана, } \\
\text { туризьм }\end{array}$ & $\begin{array}{l}\text { Заетост, } \\
\text { туризьм }\end{array}$ & $\begin{array}{l}\text { Снабдяване, } \\
\text { туризьм, } \\
\text { сигурност }\end{array}$ & $\begin{array}{l}\text { Снабляване, } \\
\text { туризьм, } \\
\text { комуникации } \\
\text { и сигурност }\end{array}$ & $\begin{array}{l}\text { Комуникации, } \\
\text { сигурност, } \\
\text { отбрана }\end{array}$ \\
\hline
\end{tabular}

Фиг. 1. Прироритети на обществения транспорт

\section{ЗАРАВЕОПАЗВАНЕ И СОЦИААНИ ГРИЖИ}

Поставени във фоокуса на социокултурното завихряне на еАин сравнително кратьк, наситен с послания и богат на Аанни И изводи кризисен периол, секторите на зАравните и социални грижи рискуват Аа бълат травматизирани още повече, отколкото функционирането им е заплашено от условностите на постоянна и трайна икономическа криза и социалната трансорормация. Безвъзвратно е пропусната и възможността за изобретяването на глокални културни решения за оптимизирано управление на сорера като мелицината с толкова изявено научно, етично И обществено значение, на водеща местна традиция неалекватно полсигурена с ресурс за изпьлнение на своите цели, вкАючително и на социално възпитание на сьзнание за 
обществена хигиена наАхвърлящо стандартите на третия свят. СлеА щеАрото приемане на свои и чужАи имигранти в крайно затруднената социална система на страната и при условия на субсилиране на престижното бьлгарско медицинско образование чрез обучение на чуждестранни стуленти и продьлжаване на традицията на полсигуряване на елитите на Аруги страни, иАва времето за внимание и към управлението на зАравеопазването и благоустройството, които потенциално $А$ а Аалат обозрими социални резултати. Фокусът на меАицинските изслеАвания върху усъвършенстване на меАицинската технология (Dimitrova, Lozanova, Lahchiev \& Roumenin, 2012) изисква и алекватно сьотнасяне към сьстоянието на зАравеопазването.

\section{Кризата в снабАяването и заетостта и панАемичните Социални} грижи като тест за обществена солиАарност И консолиАационни субкултурни тенАенции

Продьлжителното пренебрегване на белността, трудовата миграция и Аемографските проблеми в контекста на геополитически формации насочени към повишаването на глокалното благосьстояние чрез разрешаване на регионални кризи Анес изглежла спешно намира изхоА от липсата на стабилност в екстремната пандемична ситуация. Ако при изкуствено съзАаАените оптимални тестови условия за апробиране на рискови социални политики не се експлоатира потенциала на кризата $А$ отчете измерими показатели и приоритизира сектори, в пост-травматичните условия на последвалата културна реабилитация това може $а$ се окаже съвсем невъзможно. Тъй като в условия на завишен обществен натиск много от показателите за наблюление и инструментите за работа в рутинни ситуации се оказват неалекватни, сега е моментьт $\Delta$ а се приложи опита на хората с уврежАания и Аруго неравностойно положение. Привикнали, приспособили се и развили механизми за по-Аобро ориентиране в условностите на принудителния живот в изолация и постоянна ежеАневна и дори рутинна необходимост от справяне С ограниченията на социалната Аистанция и неАостьпността на голяма част от социокултурните придобивки, които Анес не са лукс за повечето хора 
както се установява при конкретното проучване на Аостъпността (Sabev 2020), (Sabev, 2017), (Sabev, Georgieva-Tsaneva, \& Bogdanova 2020), (Karagyozov, 2019) и вьпреки трудностите $\Delta$ a ce премине към нов цивилизационен етап [Фиг. 2].

\begin{tabular}{|c|c|c|}
\hline $\begin{array}{l}\text { ТЕХНИЧЕСКИ И } \\
\text { ТЕХНОАОГИЧНИ } \\
\text { ИНОВАЦИИ } \\
\end{array}$ & $\begin{array}{c}\text { АКСИОАОГИЧНИ } \\
\text { КУАТУРНИ } \\
\text { ТРАНСФОРМАЦИИ }\end{array}$ & $\begin{array}{c}\text { ПРЕОРИЕНТАЦИЯ НА } \\
\text { МАСОВИТЕ ЧОВЕШКИ } \\
\text { РЕСУРСИ }\end{array}$ \\
\hline $\begin{array}{l}\text { Компенсация на } \\
\text { човешки ресурс } \\
\text { изложен на здравен } \\
\text { риск от замьрсяване и } \\
\text { заразяване }\end{array}$ & $\begin{array}{l}\text { Инорормационно } \\
\text { полсигуряване на } \\
\text { културната } \\
\text { трансорормация } \\
\text { осъществяване чрез } \\
\text { технологични иновации }\end{array}$ & $\begin{array}{l}\text { Разработка на } \\
\text { компенсаторна } \\
\text { стратегия за } \\
\text { преололяване на } \\
\text { изоставането в } \\
\text { социокултурното } \\
\text { етичното осмисляне на } \\
\text { иновациите }\end{array}$ \\
\hline $\begin{array}{l}\text { Роботизирана техника } \\
\text { поллежаща на } \\
\text { специализирано } \\
\text { проектиране, } \\
\text { произволство, } \\
\text { оптимално } \\
\text { натоварване, ремонт и } \\
\text { дезиндекция, } \\
\text { социална алаптация }\end{array}$ & $\begin{array}{l}\text { Обезопасяване на } \\
\text { хуманни лични } \\
\text { пространства от } \\
\text { рисковете на } \\
\text { неконтролирано } \\
\text { роботизирано } \\
\text { присьствие и намеса } \\
\text { чрез усьвьршенстване } \\
\text { на комуникация човек- } \\
\text { машина-социум }\end{array}$ & $\begin{array}{l}\text { Компенсаторни } \\
\text { механизми на } \\
\text { молелиране на трудовия } \\
\text { пазар и алекватна } \\
\text { политика на релокация } \\
\text { на човешки ресурс в } \\
\text { здравеопазването и } \\
\text { благоустройството }\end{array}$ \\
\hline $\begin{array}{l}\text { Функционално } \\
\text { избягване на риска от } \\
\text { дефрицити на } \\
\text { програмирането чрез } \\
\text { интензивно събиране } \\
\text { на Аанни в екстремни } \\
\text { условия }\end{array}$ & $\begin{array}{l}\text { Развитие на алекватни } \\
\text { сьвременни } \\
\text { компетентности за } \\
\text { управление и } \\
\text { социализация на на } \\
\text { роботизирани } \\
\text { хардуерни и софртуерни } \\
\text { технологични и ресурси }\end{array}$ & $\begin{array}{l}\text { Ефективна прогностика } \\
\text { на роботизираното } \\
\text { програмиране и } \\
\text { оптимална организация } \\
\text { на релокацията на } \\
\text { масови човешки } \\
\text { ресурси от престижни и } \\
\text { приоритетни } \\
\text { икономически и } \\
\text { обществени сектори }\end{array}$ \\
\hline
\end{tabular}

Фиг. 2. Обществени нагласи към пореАна инАустриална революция

\section{ОПАЗВАНЕ НА ПРИРОАНО И КУАТУРНО НАСАЕАСТВО}

Постоянният през послеАните десетилетия риск за опазването на местното културно наследство в България поражда нехомогенни и понякога крайно противоречиви процеси на повишаване на общественото съзнание за съпричастност към общочовешките ценности. Неалекватността на местните към световните съвременни 
стандарти за икономическо полсигуряване на човешките ресурси като носители на наслеАството и стожери на общественото благополучие е трайно преАизвикателство с роля на социокултурен стимул за развитие. Непрекъснатите комплексни изследователски усилия проявени в система от културни инициативи показват резултатност значима и за приоритетните обществени сектори свързани с виАимо благоустройство и обективно измеримо социално благополучие. Катастродралните последствия за глобалното зАравеопазване по време на пандемията през март 2020 година се развиват в явен ущьрб на икономиката, но още позначителни могат $\Delta$ а се окажат културните трансорормации, които в бълеще $\Delta а$ се изтьлкуват и като окуражаващи извьн конкретния критичен контекст.

НалежАността на утвърАените и непосредствено определяните критерии и показатели на медицинската статистика при оперативното инорормационно подсигуряване на взимането на решения през този сравнително кратък времеви периол протичащ в относително огромен мащаб на обществена значимост на пандемичните явления позволява очертаването на ценни межАинни изволи още в непосреАствения хоА на така стеклите се извънреАни събития, които е възможно впослеАствие напьлно Аа загубят социална актуалност. Вписването на българските социални обстоятелства в глобалната екстрена ситуация към края на април 2020 все още се оценява като репрезентативно и очакваният епилемиологичен ефект за страната на този етап се оценяват като прогнозирано положителни. Но какви модеАи в преАстоящите сеАмици и месеци или година предстои да бъдат следвани, разработени и апробирани, все още е трудно да се предвижла и предлага. А това време е от особена важност като генериране на екстрени възможности за събиране на Аанни за медицинското програмиране и роботизацията, за тестване на иновативни решения, вкАючително и във връзка с наследството.

\section{Околната срела}

Потенциальт на местното природно богатство за постоянна психодризична рехабилитация на човешкия ресурс чрез възможността 
за общуването с естествената среда на населението и връщането към слабо населението територии още веАнъж Аоказва своята същностно хуманна ценност. Не по-малко от културното наслелство, общуването с изкуството и цялото разнообразие от мотивация за туристическа мобилност, рисковата и високо ценена и постоянно проблематизирана връзка на хората с природата чувствително премества орокуса на съвременните иновационни тьрсения от напредька на генното инженерство и редрлексиите от социалното. Отнасянето на епилемията Към Аефрицитите на регулацията на близостта с природата, рискьт за Изкуствено отгАежАаните животински виАове, особено при изкАюченията от превантивните мерки на социална изолация за извежАане на Аомашни Аюбимци и работата в земеделието и животновъАството, въпреки вредното обезАвижване и невъзможността за излизане на чист възаух за хората и общия риск от претоварване на зАравната система извежлат на преден план диагностичните процедури.

\section{Завръщането на възАействието на природата в населените} места като преАпоставка за акултурация

Психофизичните измерения на безизхолицата на принуАителната социална изолация С ефекти аналогични на ИНАИвИАУаАНо И колектИвно повеАение при беАствия И аварии труАно може социален експеримент, злоупотреби на мащабно гАока^но ниво и нови асоциални тенденции, които да бъдат преололявани с цената на същностни ресурси за положителни приАобивки Аостигат Ао паника, която причинява преразхол на Аопьлнителни усилия за обществено регулиране. Пьрвоначалната неалекватност на емблематични обществени културни фоктори с потенциал за консолидиращи функции постепенно преминава в изпьлнение на очакваните отговорности и практически роли.

Неочакваните темпове и едекти на наглеАното експериментално компенсиране на самоубийственото замьрсяване на природната среда и преустановяването на масовото непрекьснато унищожаване на природното наследство в екстрените пандемични 
условия на глобална човешка изолация, същевременно поставят в остьр психофризичен риск населението на земята, а въпреки непремерения риск от пренапрежение, показват завилен и непостижим в нормални условия спал на Аеструктивни социални яв^ения като престьпността и конориктите. Пропускането на шанса за научни измервания и изобретяване на креативни критерии и показатели за отчитане на непосредствения колективен и индивиАуален ефрект от извънреАни мерки и изкуствено предизвикани явления обхваща широк социокултурен Аиапазон от фолклорни, през статистически $А о$ инорраструктурни спонтанни решения. Настоящите Аинамични идеи за промишлена революция, интернет на нещата, културните едекти от Аобавените реалности, ръста и особеностите на роботизацията не само като сектор и практика, но и като виА призвание, възприятие и култура, новите комуникационни мрежи и технологии, вероятно са довели $\Delta о$ предпаралигмално натрупване, което очертава нетрадиционен ремолернизационен еорект на цивилизационна слелпостмодерна промяна, чието дефриниране е навлязло в напреднал Аискусионен етап нужАаещ се от екстрените обстоятелства на глобална криза или конориикт, които Аа изявят същностни културни характеристики скрити зал отАеАни маркери [Фиг. 3].

\begin{tabular}{|c|c|c|}
\hline $\begin{array}{l}\text { СОЦИААНА ЗНАЧИМОСТ } \\
\text { НА АОСТЬПНОСТТА НА } \\
\text { ПРИРОАНАТА СРЕАА }\end{array}$ & $\begin{array}{c}\text { ПРЕТОВАРВАНЕ НА МЕАИИ } \\
\text { И КОМУНИКАЦИИ }\end{array}$ & $\begin{array}{l}\text { ПРЕОАОАЯВАНЕ НА } \\
\text { ЗАМЬРСЯВАНЕТО }\end{array}$ \\
\hline $\begin{array}{l}\text { Наличие, тьрсене и } \\
\text { оптимална } \\
\text { експ^оатация на } \\
\text { приролни богатства }\end{array}$ & $\begin{array}{l}\text { Увеличение и рисковете } \\
\text { на инорормационния } \\
\text { поток и комуникационните } \\
\text { технологии }\end{array}$ & $\begin{array}{l}\text { Шум, вибрации, } \\
\text { ралиация, к^имат, } \\
\text { човекопоток, } \\
\text { населеност, моби^ност }\end{array}$ \\
\hline $\begin{array}{l}\text { Пиетет към хуманитарни } \\
\text { и приролни богатства, } \\
\text { социално управление и } \\
\text { демографрски политики }\end{array}$ & $\begin{array}{l}\text { Повишаване на } \\
\text { Аигиталната } \\
\text { компетентност и практики } \\
\text { на природосьобразен } \\
\text { начин на живот и } \\
\text { здравеопазване }\end{array}$ & $\begin{array}{l}\text { Промишлени отпальци, } \\
\text { рискови инАустрии, } \\
\text { транспортни } \\
\text { комуникации, } \\
\text { конорликти и беАствия }\end{array}$ \\
\hline
\end{tabular}

Фиг. 3. Преосмисляне на социалните приоритети на прироАнотО НаслеАство 


\section{Благоустройството и културното наслеАство}

Спешното изпьлнение на критериите за социална съобразност на голямо множество пренебрегвани Ао момента у нас условия на живот, общоприети в страните с висок икономически стандарт засяга необратимо и сектора на културното наследство в България. Въпреки недооценяването на риска в момент на криза и спешно изпьАняване на противопандемични критерии, очакванията са приетите хигиенни мерки $\Delta$ а продьлжат $\Delta$ а се по сигуряват и слеА изтичане на ограниченията при постепенната отмяна на извьнредното положение. Повишаването на този нов виА социална превантивна култура е базирано на пореактивното и рефлексивно отчитане на редица психосоматични критерии, които към момента са били грубо незачитане, въпреки прякото им отношение към правозащитните подобрения при обществените усилия и Аьржавни политики по благоустройството през послеАните Аесетилетия и все още живата памет за социалистическото организационно наследство слеА известен периол на Аемократизационно отхвърляне на негативните аспекти на засиления планиран и централизиран културен контрол.

Пандемичната самоизолация е благоприятен момент за осъзнаване на социално ниво на ползите от масовото роботизирано наблюдение на ежеАневните промени на психосоматични показатели на населението, включително усъвьршенстването на преллаганите за целите на секторите на сигурността и тьрговията сполелена ^окация и видеонаблюдение, което по този начин се превръща в живо моби^но картографриране и аудиовизуално изльчване и се поставя поА въпрос неговата визия, мисия и ценности. Впечатляващия потенциал за социална полкрепа чрез новите възможности за постоянно наблюАение на трудовите Аейности на редица профресии, например в обществения транспорт, като и социално-консолиАационните по^зи от изАъчване на живо на творческите процеси и изяви на културните и просветни Аейци Аалеч не са същите като в кризисни ситуации. Критичните екстрени обстоятелства на Аигитализация, виртуализация и роботизацията, макар и в определен момент ориентирани към твърде конкретни практични цели, показват значителен потенциал $А$ повлияват проблемната 
културна перцепция на множество нови практики и иновационни продукти като по-трайно ги пренасят от специфричната им Мотивация за изобретяване, например с военно-разузнавателни цели или за специоични нужли на хора със затруднения и увреждания, а същевременно редуцират до необхолимия разумен минимум резервите на хората порали опасения от редица рискове и злоупотреби.

\section{Възможности за живото наслеАство и рискове за материалното}

При създалата се екстрена и безпрецелентна глокална ситуация на пандемия, от енна страна се изисква бърза културна реакция на изобретяване на нови практики, а от Аруга страна възможностите за повлияване на обществени кАимат със среАствата на наслеАството и изкуството са изнесени изцяло онАайН. Преосмислянето на общностността, моби^ността, солиАарността и комуникацията се осъществява на границата на културна конфАиктност, каквато се разразява в цьрковните общности вследствие на необхолимостта от мигновена и Аинамична общностна или субкултурна трансорормация на утвърдените практики и норми. Например, в България Ауховенството е еАинственото съсловие в страната, което с риск за живота, имиАжа на вероизповеданието, ресоциализацията на религията и безопасността на кАир И паство, Кьм началото на великАенските празници все още отказва да носи предпазни средства на сакралното си работно място, което е едновременно и фоокус на призвание и вероизповедание.

Част от хората също не приемат или са склонни Аа отстраняват предпазните си средства в светите места и по време на богослужение, в различна степен при отАелните тайнства, ритуали, обичаи и рутинни навици, тъй като те нарушават изконната характерна символична образност и застрашават Аушевния коморорт на еАни хора за сметка на готовността на Аруги за рестрикции на Аеноминационните своболи. При това положение, ако се приеме като експериментално, може $а$ а се прогнозира как биха се посрещнали евентуални меАицински измервания, колкото и $а$ а е аргументирана необходимостта им 
(Bogdanova \& Galabova, 2019). Тъй като у нас Анес Ауховенството не изучава хигиена, както в миналото, а освен това, не е лобре проучена възможността за адитивно и девиантно поведение, свързана с неправи^на организация на положителните измерения на религиозността на социалната и по-специално, емоционалната интелигентност в контекста на цьрковния етнос и вероизповеАанието (Nazarska \& Shapkalova, 2018), (Nikolova, 2019) на практика възникват ИНАИвИАУаАНИ И СОЦИААНИ РИСКОве.

Самото отслабване на рестрикциите на мобилността показа, че вариращите религиозни традиции на хигиена, профрилактика, терапия и социална Аистанция са поставени на изпитание от пандемията заеАно с туристическите измерения на феестиванните практики. Рисковата Аезинфекция на храмовете като Аонякьле Аействаща част музейните и религиозни места и повишаването на сьзнанието на вярващите и туристите за обществена и лична хигиена безспорно е Аьлгоочаквана социокултурна прилобивка, която ще промени значително зАравната култура на населението и благосьстоянието на страната като цяло. Но преди в комплексна глокална перспектива да се осъзнае това обстоятелство като цивилизационна промяна, необхолимо е $а$ се осъществи социалнопсихологична превенция, която Аа подсигури постепенната, макар и принудително екстрена и крайно Аинамична обществена промяна. С продьлжаване и отслабване на принудителната изолация очакваните мерки на алекватизиране на благоустройството предстои наАхвърлят по мащаб и качество пьрвоначалното рутинно опазване на предметната среда от риска на неглижиране на опазването иे при неблагоприятни фрактори на експлоатацията.

При масовите ограничения в приАвижването и Аостьпа АО природната среда, хората затруднени в рязката потребност $А$ а преосмислят житейските си приоритети и ежеАневното си поведение и не успяващи навреме $а$ компенсират редуцирането на креативните и рекреативни възможности и без Аруго затруднени от ниския икономически стандарт и социалната стратификация е възможно $А а$ понижат своето съзнание за материално културно наследство и $а$ а 
преоткрият и възсъзАадат живото, къАето рискът от изкуственост не е помалко значим и при полобряване на Аигитализация и реално-виртуално присъствие [Фиг. 4].

\begin{tabular}{|c|c|c|}
\hline $\begin{array}{l}\text { ЖИВО КУАТУРНО } \\
\text { НАСАЕАСТВО }\end{array}$ & $\begin{array}{c}\text { НЕАВИЖИМО } \\
\text { МАТЕРИААНО КУАТУРНО } \\
\text { НАСАЕАСТВО }\end{array}$ & $\begin{array}{l}\text { АВИЖИМО МАТЕРИААНО } \\
\text { КУАТУРНО НАСАЕАСТВО }\end{array}$ \\
\hline $\begin{array}{l}\text { Ограничаване на } \\
\text { тралиционните } \\
\text { практики на } \\
\text { образование, } \\
\text { творчество, отАих и } \\
\text { развлекателна } \\
\text { индустрия }\end{array}$ & $\begin{array}{l}\text { Приоритет на } \\
\text { нерегламентирана } \\
\text { дигитализация и } \\
\text { виртуализиране на } \\
\text { посещаемостта }\end{array}$ & $\begin{array}{l}\text { Концептуална промяна } \\
\text { вьв валоризацията на } \\
\text { материалните обекти } \\
\text { като среАоточие на } \\
\text { живо наслеАство в риск }\end{array}$ \\
\hline $\begin{array}{l}\text { Проблемна } \\
\text { приоритетност на } \\
\text { културните Аейности за } \\
\text { сметка на } \\
\text { икономическата им } \\
\text { едективност и } \\
\text { управляемост и в } \\
\text { условия на криза }\end{array}$ & $\begin{array}{l}\text { Редуциране на } \\
\text { оптималната } \\
\text { експ^оатация и } \\
\text { невьзможност за } \\
\text { подАрьжка на обекти и } \\
\text { устойчиво развитие }\end{array}$ & $\begin{array}{l}\text { Аилеми на } \\
\text { представянето на } \\
\text { статични материални } \\
\text { ценности при повишена } \\
\text { необходимост от } \\
\text { динамизиране на } \\
\text { сектора }\end{array}$ \\
\hline
\end{tabular}

Фиг. 4. Критерии за критично съхранение на културно наслеАство

Медицинското програмиране и роботиката следват хода и особеностите на реалния живот с неговите потребности, но трудно могат $\Delta a$ се усьвьршенстват без абстрактните предпоставки на моделирането и създаването на изкуствен интелект, които изискват алекватна културна социализация като в същото време провокират хуманните ценности. ИнтерАисциплинарните подходи на проучване на психосоматичните показатели на хора с увреждания за целите на медицината изискват не само съвместяване на комплексната трансАисциплинарна и транскултурна проблематика на инвалиАността като модел за справяне с кризисни обстоятелства, с подходите на точните и естествените науки. Разгледаните актуални проблеми на културното осъзнаване на състоянието и нивото на ежеАневната $\triangle$ АСтьПност като комп^ексно и Аинамично приоритизирана ценност [Фиг. 5], оттам и като реална и актуална визия, мисия, нагласа, стратегия, политика и практика пряко касаят възможностите за повишаване на качеството на живот в глокален план и показват 


необходимостта от предварително научно внимание към

специфичното, което е малко вероятно Аа стане социална практика.

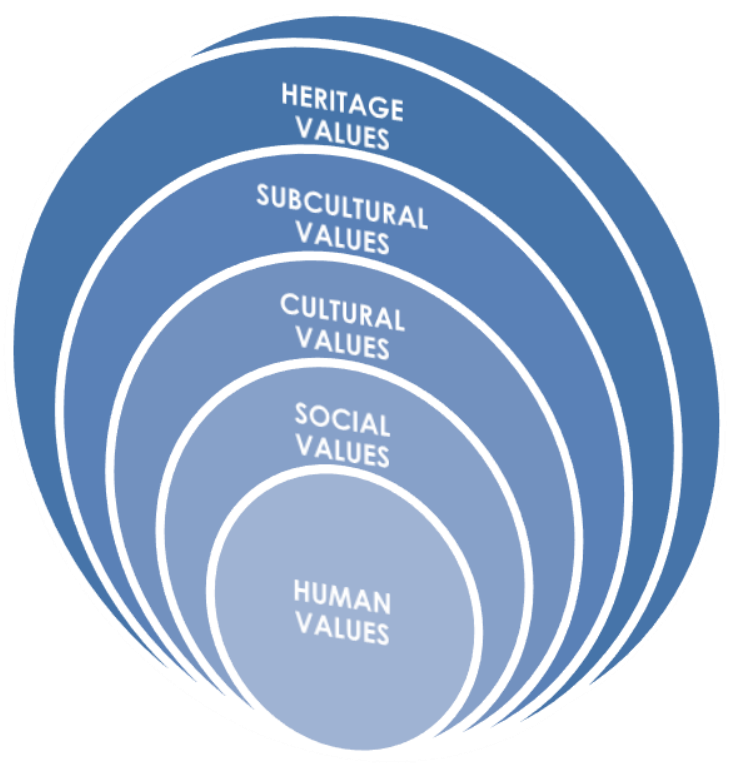

Фиг. 5. Степенуване на приоритети при повишаване на съзнание за ценности.

\section{AИTEPATYPA / REFERENCES}

Bogdanova, G.; \& Galabova, L. (2019). Mathematical Methods in Studying of Psychosomatic Parameters of Cultural Diversity on Medical Purposes. In: Zh. Nazarska \& Sv. Shapkalova, Eds. Harmony in Diversity VI, 169-178, Sofia: Za Bukvite: O Pismeneh, ISSN: 2367-7899.

Dimitrova, M.; Lozanova, S.; Lahtchev, L.; \& Roumenin, C. (2012). New Interface Technologies for Cloud Healthcare Services. - Compt. Rendus ABS, 65(1), 83-88, 6 p. IF = 0.219, ISSN: 1310-1331. 
Karagyozov, I. (2019). People with Disabilities: Solution or Problem. In: Zheorzheta Nazarska and Svetla Shapkalova, Eds. Harmony in Diversity VI. 497-505, Sofia: Za Bukvite, ISSN: 2367-7899.

Nazarska, Zh.; \& Shapkalova, S. (2018). Christian Sacraments and Religious Emotions: View on Religiousness in Contemporary Bulgaria. In: (Nazarska, Zh. \& SV. Shapkalova, Eds.) Harmony in Diversity, V. Sofia: Za Bukvite, 2018, 123-129, 7 p., ISSN: 2367-7899.

Nikolova, S. (2019). Religious Practices and Psychoanalysis (Neurosis and Ritual in Search of Truth and Harmonisation of Opposite Views on Religion). In: Nazarska, Zh. \& Sv. Shapkalova, Eds. Harmony in Diversity, VI. Sofia: Za Bukvite, 2019, 162-168, 7 P., ISSN: 2367-7899.

Sabev, N. (2017). Beneficiality of Diversity: Analysis of Beneficiality and Accessibility in Regard of Disabled. In: Zh. Nazarska and Sv. Shapkalova, Eds. Harmony in Diversity IV, 459-466, Publisher: Za Bukvite: O Pismeneh, Sofia, Bulgaria, ISSN: 2367-7899.

Sabev, N. (2020). Computer Methods and Approaches in Research and Presentation of Knowledge on Web Accessibility of Disabled People (in Bulgarian). PhD Thesis. G. Bogdanova (supervisor). Sofia: Institute of Mathematics and Informatics, Bulgarian Academy of Sciences, Bulgaria.

Sabev, N.; Georgieva-Tsaneva, G.; \& Bogdanova, G. (2020). Research, Analysis, and Evaluation of Web Accessibility for a Selected Group of Public Websites in Bulgaria, Journal of Accessibility and Design for All, 10(1), 124-160, 37 p., doi: 10.17411/jacces.v10i1.215HC5, ISSN 213-7087. 


\section{КУАТУРНО-ИСТОРИЧЕСКО НАСАЕАСТВО: \\ ОПАЗВАНЕ, ПРЕАСТАВЯНЕ, АИГИТААИЗАЦИЯ}

\section{CULTURAL AND \\ HISTORICAL \\ HERITAGE}

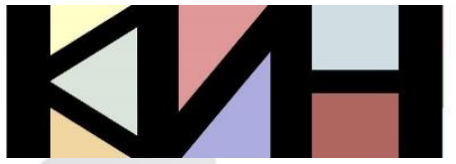

PRESERVATION PRESENTATION DIGITIZATION
Материалите в сборника са обект на авторско право. Разрешава се безвъзмезАното ползване на техни електронни/ хартиени копия само за лична употреба или обучение, при пь^но цитиране на текущата страница и слеА писмена декларация от цитиращия за Аипса на търговски намерения. За копиране пол Аруга фрорма, препубликуване или публикуване на сървъри се изисква писмено разрешение и/или заплащане.

() Авторски колектив, 2020 Техническо реАактори: Николай Ноев Калина Сотирова-Вълкова
This work is subject to copyright. Open and free of charge use of digital/hard copies of publications is granted only for personal or educational use, with full citation of the current page, and after written declaration of the quoting side for not-commercial Intention. For any other reproducing types, republishing, photocopying, recording, or any other storage retrieval system/ server written permission and/or fee is required.

(C) Authors` Group, 2020

Technical editors:

Nikolay Noev

Kalina Sotirova-Valkova

\section{Научна пореАица: том 6, брой 1 (8)/2020 Science series: vol. 6 , issue $1(8) / 2020$}

